\title{
Teste imunoenzimático com base em anticorpo monoclonal para a detecção de anticorpos contra os herpesvírus bovino tipos 1 e $5^{1}$
}

\author{
Fernando Viçosa Bauermann², Mário Celso Sperotto Brum ${ }^{3}$, Rudi Weiblen 4 \\ e Eduardo Furtado Flores ${ }^{2 *}$
}

\begin{abstract}
Bauermann F.V., Brum M.C.S., Weiblen R. \& Flores E.F. 2010. [A monoclonal antibody-based enzyme-linked immunosorbent assay for detection of antibodies to bovine herpesvirus types 1 and 5.] Teste imunoenzimático com base em anticorpo monoclonal para a detecção de anticorpos contra herpesvírus bovinos tipos $1 \mathrm{e}$ 5. Pesquisa Veterinária Brasileira 30(5):411-417. Departamento de Medicina Veterinária Preventiva, Centro de Ciências Rurais, Universidade Federal de Santa Maria, RS 97105900, Brazil. E-mail: eduardofurtadoflores@gmail.com

Bovine herpesviruses 1 (BoHV-1) and 5 (BoHV-5) are antigenic and genetically related viruses associated with different clinical syndromes in cattle, including respiratory, reproductive, neurological disease and abortion. Epidemiological studies indicate the widespread distribution of both viruses among Brazilian cattle. Serological diagnosis, that allows the identification of latently infected animals, represents an important tool for individual and herd monitoring. The present article describes the standardization of a monoclonal antibody (MAb)-based immunoenzymatic test (ELISA) for detection of antibodies to BoHV1 and/or BoHV-5. The initial steps involved the determination of the most suitable MAb, the appropriate dilutions of viral antigen and serum samples, and the cut-off value of the assay. After standardization, the ELISA was validated by testing 506 cattle serum samples previously tested for neutralizing antibodies to BoHV-1 and BoHV-5 by virus neutralizing assay (VN). Comparing to the VN for BoHV-1 antibodies, the ELISA presented sensitivity and specificity of $96.6 \%$ and $98.3 \%$, respectively. Positive and negative predictive values were $97.6 \%$, the concordance between the tests was $97.6 \%$ and the coefficient of correlation $k$ (kappa) was 0.95 , demonstrating an excellent correlation. Comparing to the VN for BoHV5 antibodies, the ELISA presented $94.3 \%$ of sensitivity, $97.9 \%$ of specificity, $97.1 \%$ of positive predictive value, $95.9 \%$ negative predictive value, concordance of $96.4 \%$ and kappa coefficient of 0.92 . These results demonstrate that the ELISA presents suitable specificity and sensitivity to be used for individual and herd serological diagnosis of BoHV1 and BoHV-5, thus, representing an alternative for VN assays and imported ELISA kits.
\end{abstract}

INDEX TERMS: ELISA, serology, bovine herpesvirus, BoHV-1, BoHV-5, diagnosis.

\footnotetext{
1 Recebido em 26 de agosto de 2009.

Aceito para publicação em 29 de dezembro de 2009 ..

2 Setor de Virologia, Departamento de Medicina Veterinária Preventiva, Centro de Ciências Rurais (CCR), Universidade Federal de Santa Maria (UFSM), Santa Maria, RS 97105-900, Brasil. Autor para correspondência: eduardofurtadoflores@gmail.com

${ }^{3}$ Setor de Virologia, Departamento de Microbiologia, Universidade

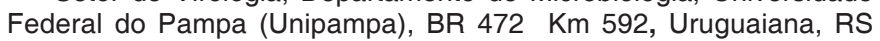
97500-970, Brasil.

${ }^{4}$ Departamento de Microbiologia e Parasitologia, CCR, UFSM, Santa Maria, RS.
}

RESUMO.- Os herpesvírus bovino tipos 1 (BoHV-1) e 5 (BoHV-5) são agentes virais genética e antigenicamente relacionados, associados com diversas manifestações clínicas em bovinos, incluindo doença respiratória, genital, neurológica e abortos. Estudos epidemiológicos indicam que esses vírus estão amplamente disseminados no rebanho bovino brasileiro. O diagnóstico sorológico, que permite identificar animais portadores da infecção latente, se constitui em importante ferramenta para monitoramento individual e de rebanho. O presente artigo relata a padroni- 
zação de um teste imunoenzimático do tipo ELISA, com base em anticorpo monoclonal (AcM), para a detecção de anticorpos séricos que reagem contra BoHV-1 e/ou BoHV5. Inicialmente, determinou-se o AcM mais adequado para a sensibilização das placas, as diluições apropriadas do antígeno e dos soros-teste e o ponto de corte do ensaio. Após a padronização, o ensaio foi validado testando-se 506 amostras de soro bovino, previamente testadas para anticorpos neutralizantes contra BoHV-1 e/ou BoHV-5 pela técnica de soroneutralização (SN). Comparando-se com os resultados da SN frente a BoHV-1, o teste de ELISA apresentou sensibilidade e especificidade de $96,6 \%$ e $98,3 \%$, respectivamente. Os valores preditivos positivo e negativo foram de $97,6 \%$, a concordância foi de $97,6 \%$ e o índice de correlação kappa entre os testes foi de 0,95, o que indica uma excelente concordância. Comparando-se com os resultados da SN frente o BoHV-5, o ELISA apresentou $94,3 \%$ de sensibilidade; $97,9 \%$ de especificidade; $97,1 \%$ de valor preditivo positivo e $95,9 \%$ de valor preditivo negativo. Para BoHV-5, a concordância entre os testes foi de $96,4 \%$ e o índice de correlação foi de 0,92, também excelente. Esses resultados demonstram que o teste padronizado apresenta sensibilidade e especificidade adequados para o diagnóstico sorológico das infecções por BoHV-1 e BoHV-5 em nível individual e de rebanho. Dessa forma, o ensaio pode se constituir em alternativa para o teste de SN e para os kits de ELISA importados.

TERMOS DE INDEXAÇÃO: ELISA, sorologia, herpesvírus bovino, BoHV-1, BoHV-5, diagnóstico.

\section{INTRODUÇÃO}

Herpesvírus bovino tipo 1 (BoHV-1) é um patógeno de distribuição mundial, com exceção de alguns países europeus que erradicaram a infecção (Ackermann \& Engels 2006). A infecção de bovinos pelo BoHV-1 está associada com doença respiratória (rinotraqueíte infecciosa, IBR), genital (vulvovaginite/balanopostite pustular, IPV/IPB), infecção sistêmica de neonatos e abortos (Kahrs 2001). Esporadicamente, o BoHV-1 também tem sido isolado de casos de doença neurológica (Silva et al. 2007). Herpesvírus bovino tipo 5 (BoHV-5) é o agente da meningo-encefalite herpética bovina, doença que possui grande importância no Brasil e na Argentina, onde dezenas de surtos são relatados a cada ano (Salvador et al. 1998, Rissi et al. 2007, Silva et al. 2007). BoHV-1 e BoHV-5 são membros do gênero Varicellovirus, subfamília Alphaherpesvirinae, família Herpesviridae (Roizmann et al. 1992) e são estreitamente relacionados entre si em aspectos genéticos/moleculares, biológicos e antigênicos (Bratanich et al. 1991, Delhon et al. 2003). Esta similaridade antigênica impossibilita a diferenciação entre esses vírus por testes sorológicos de rotina (Bratanich et al. 1991, Teixeira et al. 1998, Vogel et al. 2002). Assim, em populações bovinas onde os dois vírus circulam, os testes sorológicos não permitem distinguir a resposta sorológica contra cada um deles e, como consequência, não é possível estimar-se a prevalência de cada agente (Del Médico
Zajac et al. 2006). Tanto BoHV-1 quanto BoHV-5 estabelecem infecções latentes nos seus hospedeiros, cuja reativação periódica seguida de transmissão a animais susceptíveis representa o principal meio de perpetuação desses vírus nos rebanhos (Rock 1994, Vogel et al. 2003). Vários relatos têm demonstrado que as infecções por BoHV-1 e BoHV-5 estão amplamente disseminadas no rebanho bovino brasileiro (Salvador et al. 1998, Rissi et al. 2007, Silva et al. 2007, Holz et al. 2009).

O controle e erradicação da infecção pelos herpesvírus bovino baseiam-se na identificação e remoção dos animais soropositivos (portadores da infecção latente), associados ou não ao uso de vacinas (Van Oirschot 1999, Ackermann \& Engels 2006). O teste sorológico de referência para o diagnóstico da infecção por esses vírus é a soroneutralização (SN) (OIE). A técnica de SN apresenta boa especificidade e sensibilidade, além de ser o teste sorológico cujo princípio melhor se assemelha à neutralização de vírus por anticorpos que ocorre in vivo (Flores 2007). A necessidade de estrutura laboratorial para a manutenção de cultivos celulares, a demora na obtenção dos resultados (até $96 \mathrm{~h}$ ) e a impossibilidade de automação, no entanto, se constituem em importantes restrições ao uso da SN na rotina de muitos laboratórios, sobretudo para o teste de um grande número de amostras (Flores 2007). Testes imunoenzimáticos do tipo ELISA (enzyme linked immunosorbent assay) também são internacionalmente aceitos e muito utilizados no diagnóstico sorológico da infecção pelo BoHV-1 e apresentam como grande vantagem a possibilidade de automação e, assim, a viabilidade para diagnóstico em nível populacional (Nylin et al. 2000, Flores 2007). No entanto, os testes de ELISA anti-BoHV-1 disponíveis no Brasil são importados, e a sua utilização depende dos trâmites inerentes à importação de produtos biológicos, além do alto custo que, por vezes, inviabiliza o seu uso na rotina diagnóstica.

As restrições ao uso da SN na rotina laboratorial, sobretudo para o teste de grande número de amostras, têm motivado iniciativas para avaliar o desempenho de kits de ELISA importados e também para desenvolver testes nacionais. Médici et al. (2000) compararam a sensibilidade e especificidade de um ELISA comercial, tendo como padrão a técnica de SN, verificando $100 \%$ de sensibilidade e $94,8 \%$ de especificidade do ensaio imunoenzimático. Teixeira et al. (2001) descreveram a padronização de um ELISA monoclonal para o BoHV-1, cuja sensibilidade e especificidade em relação a SN foram de $94,7 \%$ e $89,4 \%$, respectivamente. Ferrera et al. (2005) padronizaram um teste de ELISA indireto para o BoHV-1, utilizando antígeno não purificado para a sensibilização das placas, obtendo sensibilidade de $98,3 \%$ e especificidade de $95,3 \%$ quando comparado ao teste de SN. Estes testes nacionais, apesar de apresentarem sensibilidade e especificidade geralmente satisfatórias, envolvem etapas que dificultam a produção dos kits em grande escala. Não obstante a descrição desses testes, a grande maioria dos laboratórios de diagnóstico veterinário no país prossegue utilizando a SN 
ou, ocasionalmente, kits de ELISA importados para o diagnóstico sorológico do BoHV-1. Além disso, nenhum destes trabalhos investigou a validade dos testes desenvolvidos para o diagnóstico sorológico da infecção por BoHV-5.

Dessa forma, o presente trabalho teve como objetivo desenvolver e padronizar um teste de ELISA, com base em anticorpos monoclonais (AcMs), para a detecção de anticorpos contra BoHV-1 e/ou BoHV-5. Priorizou-se a utilização de metodologia e reagentes acessíveis e de baixo custo para, assim, abrir a possibilidade de o teste ser incorporado à rotina de laboratórios de diagnóstico.

\section{MATERIAL E MÉTODOS}

A padronização e validação do teste incluíram as seguintes etapas: (1) Determinação do AcM adequado para sensibilizar as placas; (2) Produção do antígeno; (3) Determinação das diluições do antígeno e dos soros-teste; (4) Determinação do ponto de corte; (5) Validação do ELISA testando-se amostras de soro previamente testadas pela SN; (6) Cálculo da sensibilidade, especificidade, valores preditivos positivo (VPP) e negativo (VPN) e concordância do teste de ELISA em comparação com a SN.

Determinação do AcM para a sensibilização das placas. Foram avaliados três AcMs produzidos no Setor de Virologia da UFSM contra antígenos de BoHV-5 (2F9, 4E4, 3D6), mas que reagem também com antígenos do BoHV-1 (Oldoni et al. 2004). Para tal, placas de poliestireno de 96 cavidades $^{5}$ foram incubadas a $4^{\circ} \mathrm{C}$ durante $18 \mathrm{~h}$ com diluições de 1:500 a 1:32.000 de fluído ascítico de cada AcM em solução de carbonato/bicar-

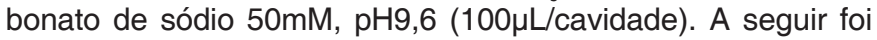
realizada uma lavagem com solução de PBS Tween $0,05 \%$ pH 7,2 e $1 \%$ de soro eqüino. Incubaram-se então as placas (300uL/ cavidade) a $37^{\circ} \mathrm{C}$ por $2 \mathrm{~h}$ com solução de bloqueio (PBS pH 7,2 + $5 \%$ de soro eqüino). $O$ anticorpo anti-lgG de camundongo, conjugado com a enzima horseradish peroxidase ${ }^{6}$ (HRP) $(100 \mu \mathrm{L} /$ cavidade, diluído 1:8.000 em solução de lavagem) foi adicionado e incubado por $1 \mathrm{~h}$ a $37^{\circ} \mathrm{C}$, seguido de 3 lavagens e adição do substrato cromógeno tetramethylbenzidine $\mathrm{TMB}^{7}$ (100 $\mu \mathrm{L} /$ cavidade). Após $15 \mathrm{~min}$, a leitura das placas foi realizada em espectrofotômetro a 650nm (KPL 2005). O AcM que apresentou o valor de DO (densidade ótica) mais adequado (4E4) foi utilizado nas demais etapas de padronização do teste.

Produção do antígeno. Uma suspensão de proteínas solúveis de células de linhagem de rim bovino CRIB (Flores \& Donis 1995) inoculadas com a cepa Cooper do BoHV-1 foi utilizada como antígeno. As células foram cultivadas em meio essencial mínimo (MEM) adicionado de $2 \%$ de soro fetal bovino, $10.000 \mathrm{UI} / \mathrm{L}$ de penicilina, $0,2 \mathrm{~g} / \mathrm{L}$ de estreptomicina e $2,5 \mathrm{mg} / \mathrm{L}$ de fungizona. Frascos de $75 \mathrm{~cm}^{2}$ contendo tapetes celulares confluentes foram inoculados com título viral de $10^{7,5}$ doses infectantes para

\footnotetext{
5 High binding 96 Well EIA/RIA Plate ${ }^{\circledR}$, Corning Incorporated, Chelmsford Street 900, Lowell, MA, USA.

${ }^{6}$ Anti mouse IgG peroxidase conjugate $\AA$, Sigma Chemicals $\mathrm{CO}$, Spruce Street 3050, St Louis, MO, USA.

${ }^{7}$ Tetramethylbenzidine $\AA$, Sigma Chemicals CO, Spruce Street 3050, St Louis, MO, USA.

${ }^{8}$ Anti bovine IgG alkaline phosphatase conjugate $₫$, Sigma Chemicals CO, Spruce Street 3050, St Louis, MO, USA.

${ }^{9}$ P-Nitrophenyl phosphate tablets $\AA$, Sigma Chemicals CO, Spruce Street 3050, St Louis, MO, USA.
}

$50 \%$ dos cultivos celulares ( DICC $_{50}$ ) e quando o efeito citopático (ECP) atingiu cerca de $90 \%$ das células, o conteúdo total dos frascos foi coletado. A infectividade viral foi inativada com solução de BEI (2-bromoetilamina) seguindo protocolo adaptado de Silva et al. (2004). Após neutralização da BEI com tiossulfato de sódio $1 \mathrm{M} \mathrm{pH} \mathrm{7,5} \mathrm{(0,32ml} \mathrm{para} \mathrm{100ml} \mathrm{de} \mathrm{antígeno),}$ a solução foi centrifugada durante $10 \mathrm{~min}$ a 2000 x g e o sobrenadante foi coletado e utilizado como antígeno. $\mathrm{O}$ antígeno negativo foi produzido da mesma forma, utilizando-se células CRIB não infectadas.

Determinação das diluições do antígeno e dos sorosteste. Para determinar-se a concentração mais adequada do antígeno, diluições na base 2 (1:5 a 1:40) em solução de lavagem $(100 \mu \mathrm{L} /$ cavidade) foram adicionadas às cavidades previamente bloqueadas e sensibilizadas com o AcM e incubadas por $1 \mathrm{~h}$ a $37^{\circ} \mathrm{C}$, seguido de três lavagens. As amostras-teste (soros bovinos positivos e negativos para BoHV-1 e BoHV-5 pela SN) diluídas 1:20 e 1:40 foram adicionadas (100 $\mu \mathrm{L} /$ cavidade) às cavidades previamente incubadas com as diferentes diluições do antígeno, seguido de incubação de $1 \mathrm{~h}$ a $37^{\circ} \mathrm{C}$ e de três lavagens. A seguir, as placas foram incubadas por $1 \mathrm{~h}$ a $37^{\circ} \mathrm{C}$ com um anticorpo anti-IgG bovina (diluído 1:60.000) conjugado com a enzima fosfatase alcalina ${ }^{8}$. Após cinco lavagens com solução de Tris $0,01 \mathrm{M}$, pH 9,6 adicionou-se o substrato nitrofenilfosfato $\left(\mathrm{pNPP}^{9}\right.$ ) na concentração de $1 \mathrm{mg} / \mathrm{mL}$. A leitura foi realizada em espectrofotômetro a $405 \mathrm{~nm}$ a intervalos de 10, 15, 20 e 30min após a adição do substrato, utilizando-se EDTA 5\% para interromper a reação. Nesta etapa determinou-se a diluição do antígeno e das amostras-teste, além do tempo ótimo para a leitura (KPL 2005).

Determinação do ponto de corte. Para o cálculo do ponto de corte, foram utilizadas 11 amostras de soro de animais provenientes de rebanhos livres do BoHV-1 e 5. Essas amostras foram testadas pelo ELISA de acordo com as condições estabelecidas nas etapas anteriores. Resumidamente, as placas de poliestireno foram incubadas com o AcM 4E4 $(100 \mu \mathrm{L} /$ cavidade diluído $1: 16.000$ ) a $4^{\circ} \mathrm{C}$ em câmara úmida por $18 \mathrm{~h}$, seguido de bloqueio durante $2 \mathrm{~h}$ a $37^{\circ} \mathrm{C}$. A metade das cavidades das placas foi adicionada de antígeno positivo (diluído $1: 5,100 \mu \mathrm{l} /$ cavidade) e o restante adicionado com o antígeno negativo, seguido de incubação a $37^{\circ} \mathrm{C}$ por $1 \mathrm{~h}$; três lavagens e incubação com as amostra-teste $(100 \mu \mathrm{L} /$ cavidade, diluídas 1:20). Assim, cada amostra de soro foi testada em duplicata, com antígeno positivo e negativo. A seguir, foram realizadas três lavagens seguidas da incubação com o anticorpo secundário anti-lgG bovina conjugado com a enzima fosfatase alcalina por $1 \mathrm{~h}$ a $37^{\circ} \mathrm{C}$. As placas foram lavadas e adicionadas do cromógeno pNPP. Após $15 \mathrm{~min}$ realizou-se a leitura da DO a $405 \mathrm{~nm}$. O valor da DO obtido de cada amostra nas cavidades pré-incubadas com o antígeno negativo foi subtraído do valor de DO obtido nas cavidades pré-incubadas com o antígeno positivo. O ponto de corte estabelecido foi a média das DOs das amostras padrão, negativas (após a subtração do valor da DO das cavidades incubadas com o antígeno negativo), acrescida de três vezes o valor de desvio-padrão, o que confere um nível de confiança de 99\% (Frey et al. 1998).

Validação do teste. O teste ELISA foi validado pelo teste de 506 amostras de soro bovino pertencentes ao banco de soro do Setor de Virologia da UFSM. As amostras foram testadas também por SN, frente a BoHV-1 e BoHV-5. A técnica de SN foi realizada de acordo com protocolos-padrão, testando-se as amostras de soro diluídas 1:2 em duplicata frente a 100 DICC $_{50}$ 
das cepas Cooper (BoHV-1) e SV-507/99 (BoHV-5). Após incubação da mistura soro + vírus por $2 \mathrm{~h}$ a $37^{\circ} \mathrm{C}$, adicionou-se uma suspensão de células CRIB e incubaram-se as placas a $37^{\circ} \mathrm{C}$ em estufa de $\mathrm{CO}_{2}$. A leitura foi realizada após $72 \mathrm{~h}$ de incubação. Amostras negativas e positivas para anticorpos contra o BoHV-1 e 5 foram utilizadas como controles. Considerando-se os resultados da SN (para os respectivos vírus) como referência, foram calculadas a especificidade, sensibilidade, valores preditivos positivo (VPP) e negativo (VPN) do ELISA e o índice de concordância entre as duas técnicas (Toma \& Vaillancourt Jean-Pierre 1999).

\section{RESULTADOS}

Como primeira etapa de padronização do teste foram testados três AcMs para a sensibilização das placas. O AcM que apresentou os maiores valores de DO foi o 4E4 (Fig.1), sendo então utilizado nas etapas seguintes. A diferença de DO observada entre os AcMs pode ser atribuída a vários fatores, incluindo concentrações diferentes das imunoglobulinas nos fluídos ascíticos e diferentes níveis de pureza, uma vez que foram utilizados fluídos ascíticos não purificados. Outro fator que pode estar envolvido com as diferentes DOs de cada AcM é a possível diferença de afinidade química dos anticorpos com a superfície da placa (KPL 2005). A diluição selecionada para uso foi de $1: 16.000$, diluição imediatamente superior ao platô de reação (KPL 2005).

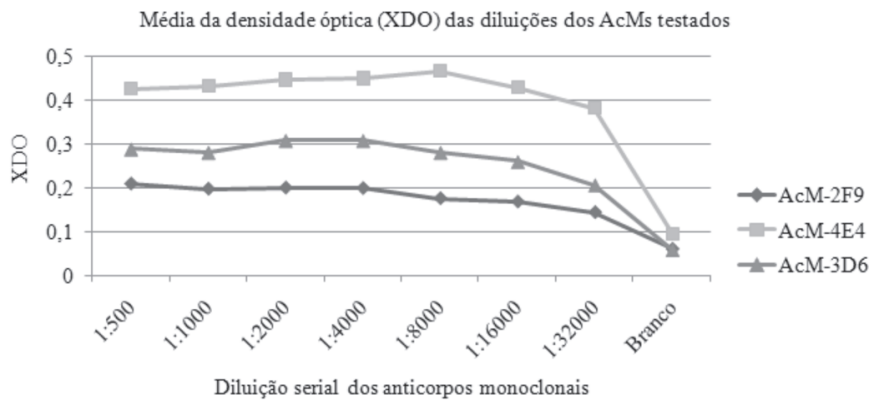

Fig.1. Média da densidade óptica (XDO) das diluições dos AcMs testados (2F9, 4E4, 3D6) para a sensibilização das placas de ELISA.

Após a seleção do AcM, testaram-se as diluições do antígeno e das amostra-teste, utilizando-se várias combinações entre essas variáveis (Fig.2). Verificou-se uma pequena variação entre os resultados, mas os valores mais elevados da DO para amostras positivas foram obtidos com a combinação da diluição de 1:5 do antígeno com a diluição de 1:20 das amostras teste. Nessa combinação não verificaram-se reações inespecíficas em níveis mais elevados do que as observadas em diluições maiores.

Após a padronização das etapas mencionadas partiuse para a validação do teste. Para tal, 506 amostras de soro bovino foram testadas pela SN frente ao BoHV-1 e frente a BoHV-5, e pelo ELISA, comparando-se então os resultados (Quadros 1-2).

Quando os resultados do ELISA foram comparados com a SN realizada frente ao BoHV-1 cepa Cooper (Quadro 1)
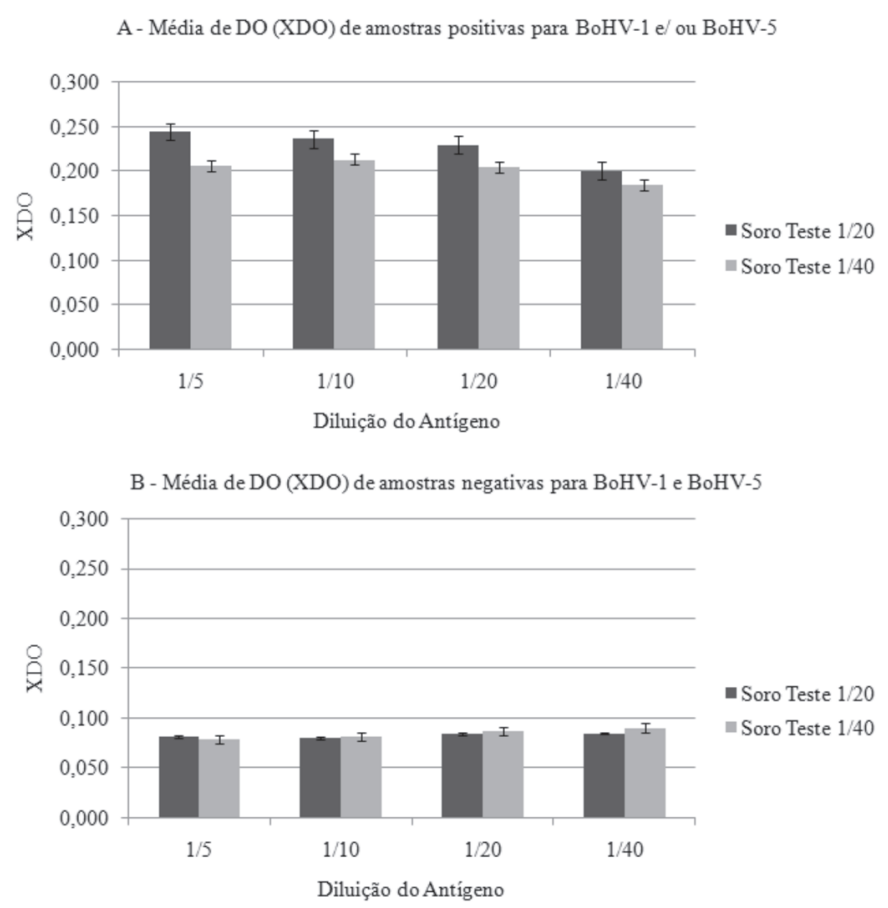

Fig.2. Média da densidade óptica (XDO) de amostras de soro positivas (A) e negativas (B) para anticorpos contra os herpesvírus bovino tipo 1 (BoHV-1) e/ou tipo 5 (BoHV-5), diluídas 1:20 e 1:40 frente a diferentes diluições do antígeno.

Quadro 1. Resultados dos testes de ELISA e soroneutralização (SN) para anticorpos contra o BoHV-1 em amostras de soro bovino

\begin{tabular}{cccc}
\hline \multirow{2}{*}{ ELISA } & \multicolumn{2}{c}{ SN BHV-1 } & \multirow{2}{*}{ Total } \\
\cline { 2 - 3 } & Positivo (\%) & Negativo (\%) & \\
\hline Positivo (\%) & $204^{\mathrm{a}}(40,3)$ & $5^{\mathrm{b}}(0,98)$ & $209^{\mathrm{a}+\mathrm{b}}(41,3)$ \\
Negativo (\%) & $7^{\mathrm{c}}(1,38)$ & $290^{\mathrm{d}}(57,3)$ & $297^{\mathrm{c}+\mathrm{d}}(58,7)$ \\
Total & $211^{\mathrm{a}+\mathrm{c}}(41,7)$ & $295^{\mathrm{b}+\mathrm{d}}(58,3)$ & $506^{\mathrm{a}+\mathrm{b}+\mathrm{c}+\mathrm{d}}(100)$ \\
\hline
\end{tabular}

Sensibilidade relativa: (a) / $(a+c) \times 100=204 / 211 \times 100=96,6 \%$. Especificidade relativa: (d) / $(b+d) \times 100=290 / 295 \times 100=98,3 \%$. Valor preditivo positivo: (a) / $(a+b) \times 100=204 / 209 \times 100=97,6 \%$. Valor preditivo negativo: (d) / (c+d) x 100 $=290 / 297 \times 100=97,6 \%$. Concordância: $(a+d) /(a+b+c+d) \times 100=494 / 506 \times 100=97,6 \%$. Kappa $=$ precisão observada $(\mathrm{PO})$ - precisão esperada $(\mathrm{PE}) / 1$ $\mathrm{PE}=0,456 / 0,477=0,95$

Quadro 2. Resultados dos testes de ELISA e soroneutralização (SN) para anticorpos contra BoHV-5 em amostras de soro bovino

\begin{tabular}{cccc}
\hline \multirow{2}{*}{ ELISA } & \multicolumn{2}{c}{ SN BHV-5 } & Total \\
\cline { 2 - 3 } & Positivo (\%) & Negativo (\%) & \\
\hline Positivo (\%) & $202^{\mathrm{a}}(39,9)$ & $6^{\mathrm{b}}(1,1)$ & $208^{\mathrm{a}+\mathrm{b}}(41,1)$ \\
Negativo (\%) & $12^{\mathrm{c}}(3,3)$ & $286^{\mathrm{d}}(56,5)$ & $298^{\mathrm{c}+\mathrm{d}}(58,9)$ \\
Total & $214^{\mathrm{a}+\mathrm{c}}(42,3)$ & $292^{\mathrm{b}+\mathrm{d}}(57,7)$ & $506^{\mathrm{a}+\mathrm{b}+\mathrm{c}+\mathrm{d}}(100)$
\end{tabular}

Sensibilidade relativa: (a) / $(a+c) \times 100=202 / 214 \times 100=94,3 \%$. Especificidade relativa: (d) / $(b+d) \times 100=286 / 292 \times 100=97,9 \%$. Valor preditivo positivo: (a) / $(a+b) \times 100=202 / 208 \times 100=97,1 \%$. Valor preditivo negativo: (d) / (c+d) $\times 100=286 / 298 \times 100=95,9 \%$. Concordância: $(a+d) /(a+b+c+d) \times 100=488 / 506 \times 100=96,4 \%$. Kappa $=$ precisão observada $(\mathrm{PO})$ - precisão esperada $(\mathrm{PE}) / 1$ $\mathrm{PE}=0,451 / 0,487=0,92$. 
verificou-se que 204 amostras (40,3\%) apresentaram resultados positivos nos dois testes; enquanto 290 amostras $(57,3 \%)$ foram negativas em ambos. No total, $494 / 506$ $(98,0 \%)$ resultados foram concordantes nos dois testes. Doze amostras (2,4\%) apresentaram resultados discordantes, sendo cinco delas $(0,98 \%)$ positivas apenas no ELISA; e sete positivas apenas na SN (1,4\%). Ou seja, o ELISA falhou em detectar $1,4 \%$ das amostras que possuíam anticorpos neutralizantes (potencialmente falsos negativos) e detectou como positivas menos de $1 \%(0,98 \%)$ de amostras negativas na SN (potencialmente falsos positivos). Comparandose com os resultados da SN frente ao BoHV-1, o ELISA apresentou sensibilidade de $96,6 \%$ e especificidade de $98,3 \%$. O VPP e VPN foram de $97,6 \%$. A concordância entre as técnicas foi de $97,6 \%$ e índice de correlação kappa foi de 0,95 , o que demonstra um alto grau de excelência do teste (Toma \& Vaillancourt Jean-Pierre 1999).

Ao comparar-se os resultados do ELISA com a SN realizada frente a BoHV-5, cepa SV-507/99 (Quadro 2), verificou-se que 202 amostras $(39,9 \%)$ foram positivas nos dois testes e $286(56,5 \%)$ resultaram negativas em ambos. Os resultados dos dois testes concordaram em $96,4 \%$ $(488 / 506)$ das amostras. Verificou-se que 12 amostras $(2,4 \%)$ foram positivas apenas na $\mathrm{SN}$ e seis $(1,2 \%)$ foram positivas apenas no ELISA. Ou seja, o ELISA resultou em $2,4 \%$ de supostos falsos negativos e em $1,2 \%$ de possíveis falsos positivos em relação a SN. Na comparação com a SN para BoHV-5, o ELISA apresentou sensibilidade de $94,3 \%$, especificidade de $97,9 \%$, VPP de $97,1 \%$ e VPN de $95,9 \%$. O índice de correlação de 0,92 observado demonstra um alto grau de excelência do teste (Toma \& Vaillancourt Jean-Pierre 1999).

Dentre as 12 amostras que foram negativas no ELISA e positivas na SN para BoHV-5, seis (50\%) também foram positivas para o BoHV-1 apenas na SN. Esses resultados sugerem que estas amostras realmente são positivas para anticorpos contra um destes vírus, porém, provavelmente apresentam títulos baixos de anticorpos, e devido ao elevado ponto de corte não foram identificadas como positivas no ELISA. O número de amostras positivas para BoHV5 apenas no ELISA foi de seis (1,18\% do total). Dentre estas, três $(50 \%)$ foram também positivas apenas no ELISA quando comparado com a SN para o BoHV-1. Como a SN detecta apenas anticorpos com atividade neutralizante, é possível que estas amostras contivessem níveis baixos de anticorpos com atividade neutralizante, indetectáveis na SN e apenas detectadas no ELISA.

\section{DISCUSSÃO}

O presente artigo relata a padronização e validação de um ELISA com base em AcM para a detecção de anticorpos séricos que reagem com BoHV-1 e BoHV-5. O ensaio desenvolvido apresenta como principais propriedades: facilidade e simplicidade de padronização e execução; custo baixo; baixa freqüência de falsos positivos e falsos negativos; aplicabilidade para a detecção de anticorpos que reagem contra BoHV-1 e/ou BoHV-5. Essas propriedades o credenciam a ser utilizado na rotina de diagnóstico sorológico desses dois vírus, podendo representar uma alternativa para a SN e também em substituição a kits de ELISA importados.

Testes imunoenzimáticos do tipo ELISA, em diversas variações e configurações, são amplamente utilizados na Europa e nos Estados Unidos para a identificação de animais soropositivos para o BoHV-1, e também na vigilância em países que erradicaram o agente (Wellenberg et al. 2001, Ackermann \& Engels 2006). Um número de artigos relata a avaliação da sensibilidade e especificidade destes testes, entre si, e em comparação com a SN, considerado o teste padrão (Bratanich et al. 1990, Kramps et al. 1993, Perrin et al. 1993). Em geral, testes de ELISA apresentam sensibilidade levemente superior a SN, mas o inverso também tem sido relatado (Bratanich et al. 1990, Kramps et al. 1993, Perrin et al. 1993, Kramps et al. 2004).

No Brasil, a utilização do ELISA no diagnóstico sorológico do BoHV-1 ainda é restrita devido a necessidade de importação dos kits, o que torna o seu custo elevado. No país já foram padronizados alguns testes de ELISA para a detecção de anticorpos contra o BoHV-1 (Teixeira et al. 2001, Ferrera et al. 2005). No entanto, esses testes não estão disponíveis comercialmente nem são disponibilizados a outros laboratórios. Além disso, os resultados desses ensaios não foram validados para verificar se detectam anticorpos que reagem com BoHV-5 na SN, vírus que também apresenta uma ampla disseminação no rebanho bovino do país e que reage sorologicamente com o BoHV1 (Bratanich et al. 1991, Teixeira et al. 1998, Vogel et al. 2002). Dessa forma, a grande maioria dos laboratórios de diagnóstico virológico no país continua utilizando a SN como teste sorológico para esses vírus, não obstante as dificuldades e restrições que o teste apresenta, sobretudo a dificuldade de teste de um grande número de amostras (Flores 2007).

O objetivo principal deste trabalho foi desenvolver um teste prático, de custo acessível de fácil produção e execução. Além disso, priorizou-se a necessidade de detectar-se amostras que reagissem contra BoHV-5 com especificidade e sensibilidade semelhantes ao BoHV-1. Pela dificuldade de obtenção de antígenos virais e AcMs com alto grau de pureza, optou-se por desenvolver um ELISA sanduíche, de acordo com recomendações técnicas (KPL 2005). Uma etapa da padronização do ensaio envolveu o teste de amostras de soro frente a cavidades sensibilizadas com proteínas de células infectadas (antígeno positivo) e não-infectadas (antígenos negativo), para obter-se o valor basal de reação com as proteínas celulares. Dessa forma, excluiu-se do cálculo o valor de DO referente ao background de reações não-específicas. Essa estratégia mostrou-se eficiente, pelo alto nível de concordância observado entre o ELISA e a SN.

$O$ teste de ELISA de bloqueio desenvolvido por Teixeira et al. (2001) utilizou antígeno não purificado para a sensibilização das placas, e não realizou-se o bloqueio de ligações inespecíficas. Isso provavelmente contribuiu para 
o número considerável de reações inespecíficas, o que reduziu a especificidade do teste para aproximadamente $89 \%$. O valor de sensibilidade $(94,7 \%)$ também ficou abaixo daquele obtido no presente trabalho $(96,6 \%$ para o BoHV1). Este ensaio também não foi comparado com a SN frente a BoHV-5.

No trabalho de Ferrera et al. (2005), obtiveram-se valores elevados de sensibilidade $(98,3 \%)$ e especificidade $(95,2 \%)$ quando comparou-se com a SN frente ao BoHV-1, com intervalo de confiança de $95 \%$. A sensibilidade foi levemente superior ao do presente trabalho $(96,6 \%)$, porém a especificidade foi inferior $(98,3 \%)$. A maior especificidade no presente ELISA pode ser parcialmente devida à subtração do background de reação das amostras frente à antígeno negativo. Além disso, a metodologia utilizada para a purificação do antígeno naquele trabalho foi bastante complexa, envolvendo separação em frações e tratamento separado para cada fração. Esta complexidade dificulta a produção e execução do teste em grande escala. O ensaio desenvolvido por Ferrera et al. (2005) também não foi comparado com a SN frente a BoHV-5.

No presente trabalho, o ELISA padronizado apresentou correlação de $97,6 \%$ com a SN para o BoHV-1 e de $96,4 \%$ com a SN para BoHV-5. A diferença de correlação com a SN para os dois vírus pode ser, em parte, devida à utilização de antígenos da cepa Cooper (BoHV-1) no teste. Isso poderia levar a detecção de um número maior de animais com anticorpos contra o BoHV-1. Animais previamente infectados pelo BoHV-1 e que possuíam títulos neutralizantes baixos, poderiam ser negativos na SN frente a BoHV-5, mas seriam detectados no ELISA.

Dentre o total de 506 amostras, 485 (95,8\%) tiveram resultados iguais no ELISA e SN frente a BoHV-1 e BoHV5. Isso demonstra que mesmo com a utilização de uma cepa de BoHV-1 (Cooper) como antígeno, a semelhança antigênica entre BoHV-1 e BoHV-5 possibilita uma identificação, com alta sensibilidade, de animais soropositivos para cada um e/ou para ambos agentes.

As pequenas diferenças antigênicas existentes entre BoHV-1 e BoHV-5 podem resultar em títulos diferentes na $\mathrm{SN}$, que são detectáveis quando amostras de soro de animais infectados por um destes vírus são testadas em paralelo frente aos dois (Holz et al. 2009). Por isso, às vezes é possível inferir a especificidade da atividade neutralizante detectada no soro, com base na comparação dos títulos frente aos dois agentes (Teixeira et al. 1998, Vogel et al. 2002). No entanto, essa diferenciação nem sempre é possível, e uma parcela considerável de amostras com anticorpos neutralizantes reage em diluições iguais tanto com o BoHV-1 quanto com BoHV-5 (Flores 2009). Como o teste aqui desenvolvido produz resultados apenas qualitativos (positivo/negativo), não permite a diferenciação entre os dois agentes. Ou seja, resultados positivos no ELISA indicam a presença de anticorpos contra um destes vírus (e que reagem também com o outro) ou, ocasionalmente, contra os dois vírus, em casos de coinfecção.

As pequenas diferenças de sensibilidade e especifici- dade observadas quando se compararam os resultados do ELISA com a SN frente a BoHV-1 e BoHV-5 a priori, não comprometem a utilização do ensaio, pois mesmo a SN quando realizada frente aos dois vírus (e mesmo frente a diferentes isolados do mesmo vírus) apresenta um percentual significativamente maior de resultados discordantes (Roehe et al. 1997, Holz et al. 2009).

Do ponto de vista epidemiológico, a dificuldade de distinção sorológica entre BoHV-1 e BoHV-5 impossibilita o conhecimento acerca da prevalência e distribuição de cada um destes agentes, sobretudo em rebanhos onde os dois vírus circulam, como é o caso do Brasil. Do ponto de vista de controle, no entanto, a impossibilidade de diferenciação sorológica não possui uma repercussão tão relevante, pois as medidas de combate recomendadas para os dois agentes são semelhantes, devido às suas semelhanças biológicas e epidemiológicas (Flores 2007).

Dessa forma, o teste padronizado apresenta as propriedades desejáveis em um teste sorológico e pode, assim, ser utilizado em substituição a SN e aos kits de ELISA importados na rotina laboratorial. Dentre os usos potenciais do teste destacam-se estudos soro-epidemiológicos, monitoramento de rebanhos e diagnóstico individual. Eventualmente, este ensaio pode ser utilizado em programas de combate às infecções por BoHV-1 e BoHV-5, seja em nível de rebanho ou em nível regional ou nacional.

\section{REFERÊNCIAS}

Ackermann M. \& Engels M. 2006. Pro and contra IBR-eradication. Vet. Microbiol. 113(3/4):293-302.

Bratanich A.C., Sardi S.I., Smitsaart E.N. \& Schudel A.A. 1991. Comparative studies of $\mathrm{BHV}-1$ variants by in vivo-in vitro tests. J. Vet. Med. 38(1):41-48.

Bratanich A., Sardi S., Smitsaart E., Estevez Madero J. \& Schudel A.A. 1990. Comparison of three serological techniques for the diagnosis of bovine herpesvirus type 1: Serum neutralization, enzyme-linked immunosorbent assay and indirect immunofluorescence. Revta Argent. Microbiol. 22(8):192-198.

Del Médico Zajac M.P., Puntel M., Zamorano P.I., Sadir A.M. \& Romera S.A. 2006. BHV-1 vaccine induces cross-protection against BHV-5 disease in cattle. Res. Vet. Sci. 81(3):327-334.

Delhon G., Moraes M.P., Lu Z., Flores E.F., Weiblen R. \& Rock D. 2003. Genome of bovine herpesvirus type 5. J. Virol. 77:1033910347.

Ferrera M.C., Médici K.C., Alfieri A.F. \& Alfieri A.A. 2005. Desenvolvimento e avaliação de um ensaio imunoenzimático para o diagnóstico sorológico da infecção pelo herpesvírus bovino tipo 1. Semina, Ciênc. Agr. 26(3):363-372.

Flores E.F. \& Donis R.O. 1995. Isolation of a mutant MDKB cell line resistant to bovine viral diarrhea virus infection due to a block in viral entry. Virology 218:565-575.

Flores E.F. 2007. Diagnóstico Laboratorial das Infecções Víricas, p.295326. In: Ibid. (Ed.), Virologia Veterinária. Editora da UFSM, Santa Maria.

Flores E.F. 2009. Comunicação pessoal (Universidade Federal de Santa Maria, Santa Maria, RS).

Frey A., Di Canzio J. \& Zurakowski D. 1998. A statistically defined endpoint titer determination method for immunoassays. J. Immunol. Methods. 221(1/2):35-41.

Holz C.L., Cibulski S.P., Teixeira T.F., Batista H.B.C.R., Campos F.S., 
Silva J.R., Varela A.P.M., Cenci A., Franco A.C. \& Roehe P.M. 2009. Soroprevalência de herpesvírus bovinos tipos 1 e/ou 5 no Estado do Rio Grande do Sul. Pesq. Vet. Bras. 29(9)767-773.

Karhs R.F. 2001. Infectious bovine rhinotracheitis and infectious pustular vulvovaginitis, p.159-170. In: Ibid. (Ed.), Viral Disease of Cattle. $2^{\text {nd }}$ ed. lowa State University, Ames.

KPL. 2005. Technical Guide for ELISA. Acessado em 23 abr. http:// www.kpl.com/docs/techdocs/KPLELISATechnicalGuide.pdf. Acesso em 23 abr. 2009

Kramps J.A., Quak S., Weerdmeester K. \& Van Oirschot J.T. 1993. Comparative study on sixteen enzyme-linked immunosorbent assays for the detection of antibodies to bovine herpesvirus 1 in cattle. Vet. Microbiol. 35(1/2):11-21.

Kramps J.A., Banks M., Beer M., Kerkhofs P., Perrin M., Wellenberg G.J. \& Oirschot J.T. 2004. Evaluation of tests for antibodies against bovine herpesvirus 1 performed in national reference laboratories in Europe. Vet. Microbiol. 102(3/4):169-181.

Médici K.C., Alfieri A.F. \& Alfieri A.A. 2000. Ensaio imunoenzimático comercial no diagnóstico sorológico das infecções por herpesvírus bovino 1. Ciência Rural 30(2):343-346.

Oldoni I., Weiblen R., Inkelmann M.A. \& Flores E.F. 2004. Production and characterization of monoclonal antibodies to a Brazilian bovine herpesvirus type 5. Braz. J. Med. Biol. Res. 37(2):213-21.

Perrin B., Bitsch V., Cordioli P., Edwards S., Eloit M., Guérin B., Lenihan P., Perrin M., Rønsholt L. \& Van Oirschot J.T. 1993. A European comparative study of serological methods for the diagnosis of infectious bovine rhinotracheitis. Rev. Sci. Tech. 12(3):969-984.

Rissi D.R., Rech R.R., Flores E.F., Kommers G.D. \& Barros C.S.L. 2007. Meningoencefalite por herpesvírus bovino-5. Pesq Vet. Bras. 27(7):261-268

Rock D.L. 1994. Latent infection with bovine herpesvirus type 1. Sem Virol. 5(3):233-240.

Roizmann B., Desrosiers R.C., Fleckenstein B., Lopez C., Minson A.C. \& Studdert M.J. 1992. The family Herpesviridae: An update. The Herpesvírus Study Group of the Internacional Committee on Taxonomy of Viruses. Arch. Virol.123(3/4):425-449.

Roehe P.M., Silva T.C., Nardi N.B., Oliveira L.G. \& Rosa J.C.A. 1997. Diferenciação entre os vírus da rinotraqueíte bovina infecciosa (BHV-
1) e herpesvírus da encefalite bovina (BHV-5) com anticorpos monoclonais. Pesq. Vet. Bras. 17(1):41-44.

Salvador S.C., Lemos R.A.A., Riet-Correa F., Roehe P.M. \& Osorio A.L.A.R. 1998. Meningoencefalite causada por herpesvírus bovino-5 no Mato Grosso do Sul e São Paulo. Pesq. Vet. Bras. 18(2):7683

Silva L.C, Takiuchi E., Médici K.C., Alfieri A.F. \& Alfieri A.A. 2004. Avaliação da capacidade adjuvante do cloreto de dimetildioctadecilamônio associado ao hidróxido de alumínio na indução da resposta imune humoral de bovinos vacinados com o vírus da diarréia viral bovina. Braz. J. Vet. Res. Anim. Sci. 41(3):201-206.

Silva M.S., Brum M.C.S., Weiblen R. \& Flores E.F. 2007. Identificação e diferenciação de herpesvírus bovino tipos 1 e 5 isolados de amostras clínicas no centro-sul do Brasil, Argentina e Uruguai (19872006). Pesq. Vet. Bras. 27(10):403-408.

Teixeira M.B., Esteves P.A. \& Coelho C.S.S. 1998. Diferenças em níveis de anticorpos contra herpesvírus bovinos tipos 1 e 5 . Pesq. Agropec. Gaúcha 4(1):61-65.

Teixeira M.F.B., Esteves P.A., Schmidt C.S., Spilki F.R., Silva T.C., Dotta M.A. \& Roehe P.M. 2001. ELISA de bloqueio monoclonal para o diagnóstico sorológico de infecções pelo herpesvírus bovino tipo 1 (BHV-1). Pesq. Vet. Bras. 21(1):33-37.

Toma B. \& Vaillancourt Jean-Pierre. 1999. Dictionary of Veterinary Epidemiology. lowa State University Press, Ames. 284p.

Vogel F.S.F., Flores E.F., Weiblen R. \& Kunrath C.F. 2002. Atividade neutralizante anti-herpesvírus bovino tipos 1 e 5 no soro de bovinos imunizados com vacinas contra o BHV-1. Ciência Rural 32(5):881883.

Vogel F.S., Caron L., Flores E.F., Weiblen R., Winkelmann E.R., Mayer S.V. \& Bastos R.G. 2003. Distribution of bovine herpesvirus type 5 DNA in the central nervous system of latently, experimentally infected calves. J. Clin. Microbiol. 41(10):4512-4520.

Van Oirschot J.T. 1999. Bovine viral vaccines, diagnostics, and eradication: Past, present, and future. Adv. Vet. Med. 41:197-216.

Wellenberg G.J. Mars M.H. \& Van Oirschot J.T. 2001. Antibodies against bovine herpesvirus (BHV) 5 may be differentiated from antibodies against BHV1 in a BHV1 glycoprotein E blocking ELISA. Vet. Microbiol. 78(1):79-84. 